\title{
KARAKTERISASI KETAHANAN LELAH TAKIK ULIR WHITWORTH AKIBAT PEMBEBANAN PUNTIR DINAMIS PADA BAJA KARBON RENDAH
}

\author{
A Hasan Atho'ullah', Heri Yudiono ${ }^{2}$ \\ ${ }^{1,2}$ Pendidikan Teknik Mesin Fakultas Teknik Universitas Negeri Semarang \\ E-mail: heri_yudiono@mail.unnes.ac.id
}

\begin{abstract}
This study aims to analyze Whitworth thread's fatigue characterization due to dynamic twisting on low carbon steel. The research method uses experiments with pre-experimental design with the form of intact group comparison. The experimental group was specimens with Whitworth thread notch depth of $0.67 \mathrm{~mm}, 0.81 \mathrm{~mm}$, and $1.16 \mathrm{~mm}$. The control group was Whitworth threads with a notch depth of $0.9 \mathrm{~mm}$. The study used low carbon steel with a carbon content of $0.12 \%$ wt. The dynamic torsion testing with a twisting angle of 5 reveals that the deeper the Whitworth thread notch, the lower the fatigue resistance. The fracture surface is visible due to dynamic torsion in the form of initial crack, crack propagation rate, and final crack.
\end{abstract}

Keywords: whitworth thread, dynamic twisting, fatigue, fracture surface area

\begin{abstract}
ABSTRAK
Fenomena kegagalan lelah disebabkan oleh pola pembebanan dan bentuk takikan. Pola pembebanan terjadi karena puntir lentur dan puntir dinamis. Bentuk takikan diperlukan karena tuntutan desain, salah satunya adalah takik ulir whitworth. Penelitian ini bertujuan untuk menganalisis karakterisasi ketahanan lelah ulir whitworth akibat pembebanan puntir dinamis pada baja karbon rendah. Metode penelitian menggunakan eksperimen dengan pre-experimental design dengan bentuk intact-group comparison. Kelompok eksperimen adalah spesimen dengan kedalaman takik ulir whitworth $0.67 \mathrm{~mm}, 0.81 \mathrm{~mm}$, dan $1.16 \mathrm{~mm}$. Kelompok kontrol dengan kedalaman takik ulir whitworth sebesar $0.9 \mathrm{~mm}$. Penelitian menggunakan baja karbon rendah dengan kandungan karbon sebesar $0.12 \%$ wt. Hasil pengujian puntir dinamis mengungkapkan bahwa semakin dalam takik ulir withworth maka ketahanan lelahnya semakin menurun. Bentuk penampang patah akibat pembebanan puntir dinamis berupa initial crack, crack propagation rate dan final crack.
\end{abstract}

Kata kunci: ulir whitworth, puntir dinamis, ketahanan lelah, bentuk penampang patah

\section{PENDAHULUAN}

Data yang dimiliki melalui pengujian tidak menjamin komponen bebas dari kegagalan, karena dalam proses perancangan disain pada umumnya menggunakan data tegangan statis. Kenyataan yang terjadi pada suatu komponen menunjukkan bahwa tegangan yang berfluktuasi disebabkan oleh getaran, semakin tinggi getaran maka waktu patah semakin cepat (Cesnik, 2014: 339-348), konsentrasi tegangan semakin tinggi maka semakin cepat patah (Agrawal et al., 2014: 69-72, Mohamed et al., 2018: 3262-3277) dan temperatur semakin tinggi maka ketahanan lelah semakin menurun (Hussain, 2016: 2324-2335).
Tegangan fluktuasi besarnya lebih kecil dari tegangan maksimum ataupun tegangan luluh (yield) yang diberikan pada beban konstan, karena terjadi dalam periode yang lama dan berbentuk siklus, maka komponen akan mengalami kegagalan (failure). Proses di mana tegangan terjadi hingga komponen mengalami kegagalan (failure) disebut dengan kelelahan (fatigue). Ketahanan lelah dapat ditingkatkan dengan menambahkan substansi seperti methylene diphenyl diisocyanate (MDI) (Chou et al.,2019) atau diberikan perlakuan panas (Ha et al., 2013: 389-393, La Rosa et al., 2017: 1-12). 
Salah satu komponen mesin yang mengalami kegagalan adalah baut. Baut berfungsi untuk menggabungkan komponenkomponen agar menjadi satu-kesatuan. Baut sering dijumpai di kendaraan bermotor, pesawat, produk telekomunikasi dan lain sebagainya. Baut memiliki jenis ulir yang berbentuk takik V, konsentrasi tegangan yang dimiliki lebih tinggi dibandingkan dengan takik U (Itoh et al., 2013: 50-60). Semakin tinggi nilai konsentrasi tegangan, maka laju retakan akan semakin tingi (Liu et al., 2013: 1161-1169). Baut dapat mengalami kegagalan (failure) dalam fungsinya. Kegagalan yang sering dijumpai ketika motor dilakukan service, mesin-mesin kapal atau pabrik dimaintenance dan mesin-mesin pesawat yang direpair. Baut akan dibuka-tutup untuk mengecek komponen-komponen mesin yang ditreatment. Proses buka-tutup tersebut mengakibatkan baut mengalami pemuntiran secara dinamis. Proses ini terjadi secara terusmenerus hingga menjadi siklus. Siklus ini sangat mungkin menyebabkan baut patah. Patah dimulai pada permukaan baut karena permukaan sangat berpengaruh terhadap ketahanan lelah (Arola dan Wiliams, 2002: 923-930, Fatemi et al., 2017). Semakin kasar permukaan, maka kemungkinan terjadinya retak awal semakin tinggi dan dapat terjadi dimanapun karena bersamaan dengan peningkatan ketahanan pada titik crack (Alang et al., 2011: 160-163, Shang et al., 2007: 2200-2207).

Baut akan mengalami kegagalan (failure) karena kelelahan (fatigue). Kegagalan baut tersebut terjadi ketika baut tersebut dikencangkan atau dilepaskan setelah komponen beberapa kali diservice atau direpair. Kegagalan tersebut berupa patahan (fracture) baut di daerah ulir. Kegagalan baut bahkan bisa lebih cepat ketika baut dipasang terlalu kencang atau longgar ketika komponen sudah beberapa kali diservice atau direpair. Kegagalan tersebut berkaitan dengan ketahanan lelah puntir dinamis. Penelitian ini dilakukan untuk menganalisa ketahanan lelah takik ulir withworth akibat pembebanan puntir dinamis.

\section{METODE}

Penelitian ini menggunakan metode eksperimen dengan pre-experimental design dengan bentuk intact-group comparison. Penelitian dibagi menjadi 2 kelompok, yaitu kelompok kontrol dan kelompok eksperimen. Kelompok kontrol terdiri dari spesimen yang diberi kedalaman takik ulir withworth $0,9 \mathrm{~mm}$. Kelompok eksperimen terdiri dari spesimen dengan kedalaman takik ulir 0,67 mm; 0,81 mm; dan 1,16 mm. Bahan yang digunakan dalam penelitian ini adalah baja karbon rendah. Dimensi spesimen uji puntir dinamis menggunakan standar JIS Z 2274 No. 1. Proses uji fatik menggunakan mesin uji puntir dinamis seperti ditunjukkan pada Gambar 1. Teknik analisis data menggunakan analisis statistik deskriptif.

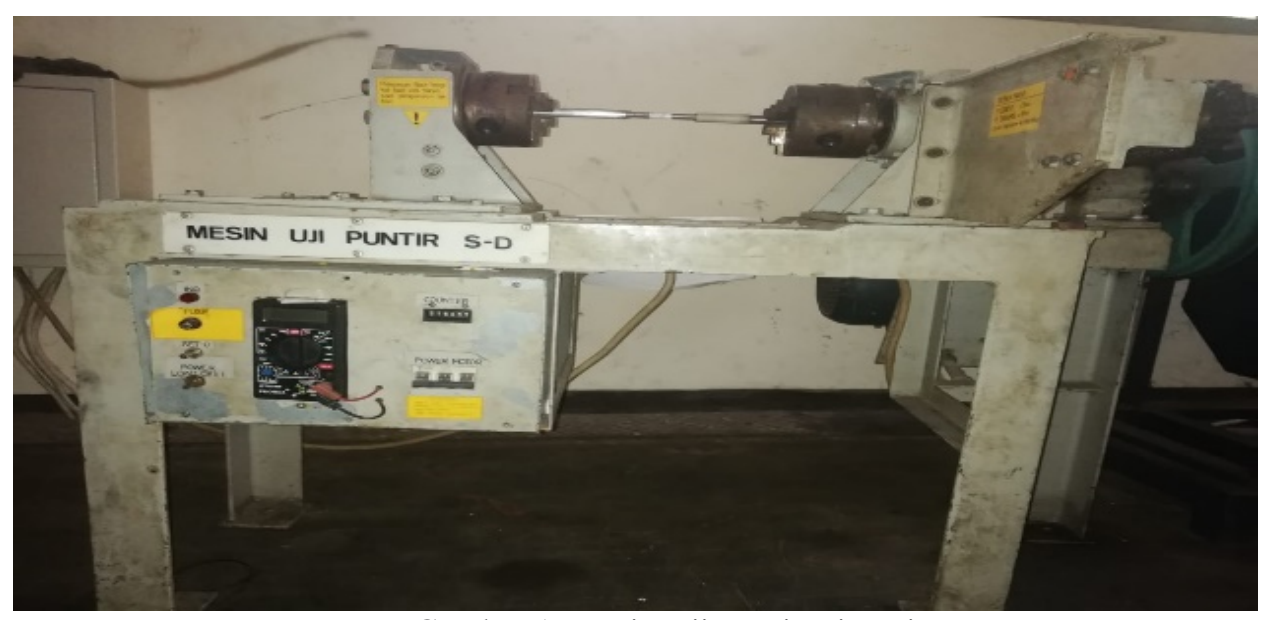

Gambar 1. Mesin Uji Puntir Dinamis 


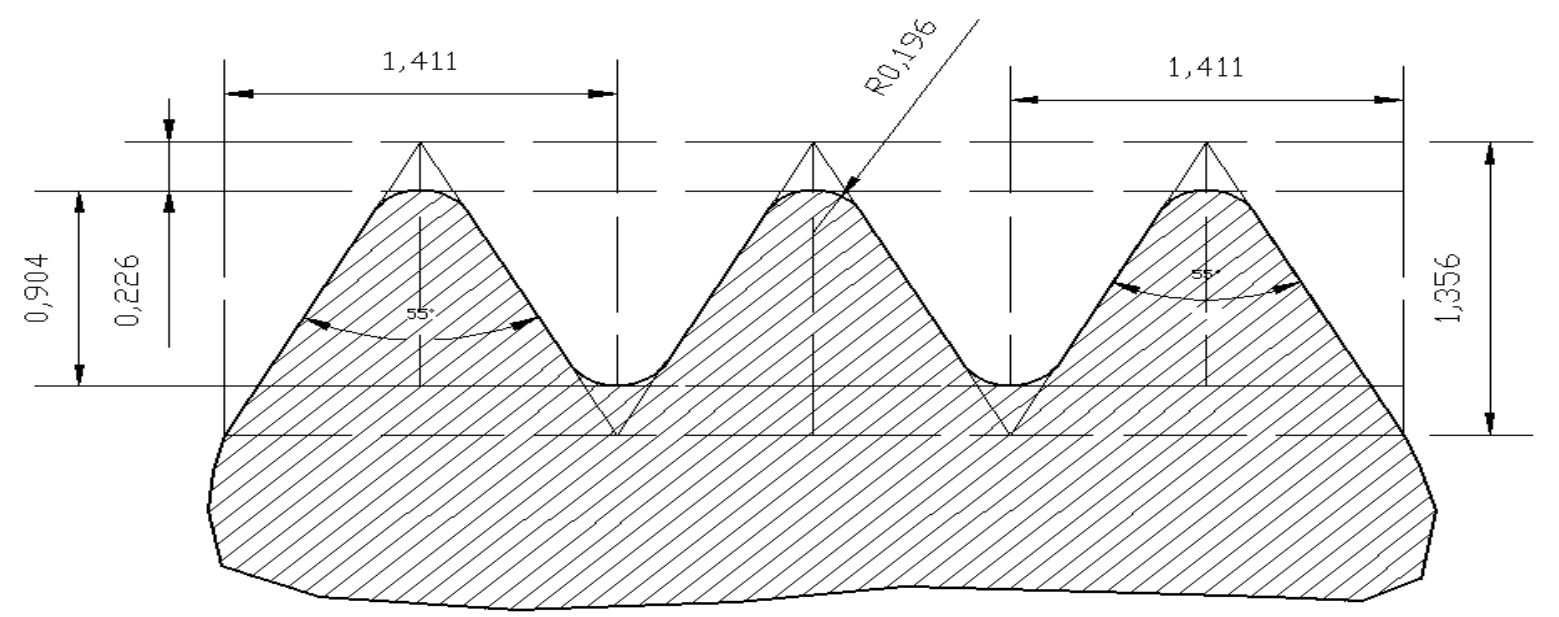

Gambar 2. Dimensi Spesimen Standar JIS 2274 No. 1

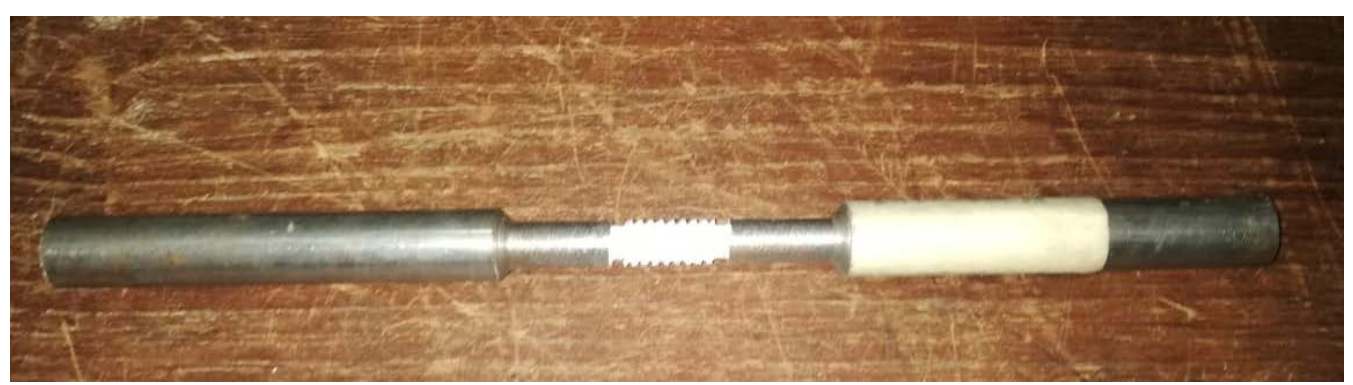

Gambar 3. Spesimen Uji Puntir Dinamis

\section{HASIL DAN PEMBAHASAN}

Pengujian komposisi dilakukan untuk memastikan kandungan komposisi yang terdapat pada bahan baja karbon rendah. Hasil pengujian seperti ditunjukkan pada Tabel 1.

Tabel 1. Hasil Pengujian Komposisi Raw Materials

\begin{tabular}{cc|cc}
\hline Unsur & Kadar (\%) & Unsur & Kadar (\%) \\
\hline $\mathrm{Fe}$ & 98.01331 & $\mathrm{Co}$ & 0.01171 \\
$\mathrm{C}$ & 0.12192 & $\mathrm{Cu}$ & 0.00513 \\
$\mathrm{Si}$ & 0.09951 & $\mathrm{Nb}$ & 0.02898 \\
$\mathrm{Mn}$ & 0.55257 & $\mathrm{Ti}$ & 0.000000 \\
$\mathrm{P}$ & 0.00152 & $\mathrm{~V}$ & 0.00000 \\
$\mathrm{~S}$ & 0.03075 & $\mathrm{~W}$ & 0.01760 \\
$\mathrm{Cr}$ & 0.01892 & $\mathrm{~Pb}$ & 0.00649 \\
$\mathrm{Mo}$ & 0.02469 & $\mathrm{Cs}$ & 0.00794 \\
$\mathrm{Ni}$ & $\mathrm{Zr}$ & 0.00294 \\
$\mathrm{Al}$ & 0.04595 & & \\
\hline
\end{tabular}

Tabel 1 menunjukkan bahwa kandungan Karbon (C) pada material specimen uji puntir dinamis sebesar 0,12\%wt. Berdasarkan hasil pengujian komposisi tersebut, baja yang digunakan dalam pengujian termasuk baja karbon rendah karena mengandung karbon kurang dari 0.25\% (Callister dan William, 2011).
Pengujian struktur mikro dilakukan pada spesimen uji bahan baja karbon rendah menggunakan mikroskop optic dengan perbesaran 500x. Hasil pengujian struktur mikro seperti ditunjukkan pada Gambar 4. 


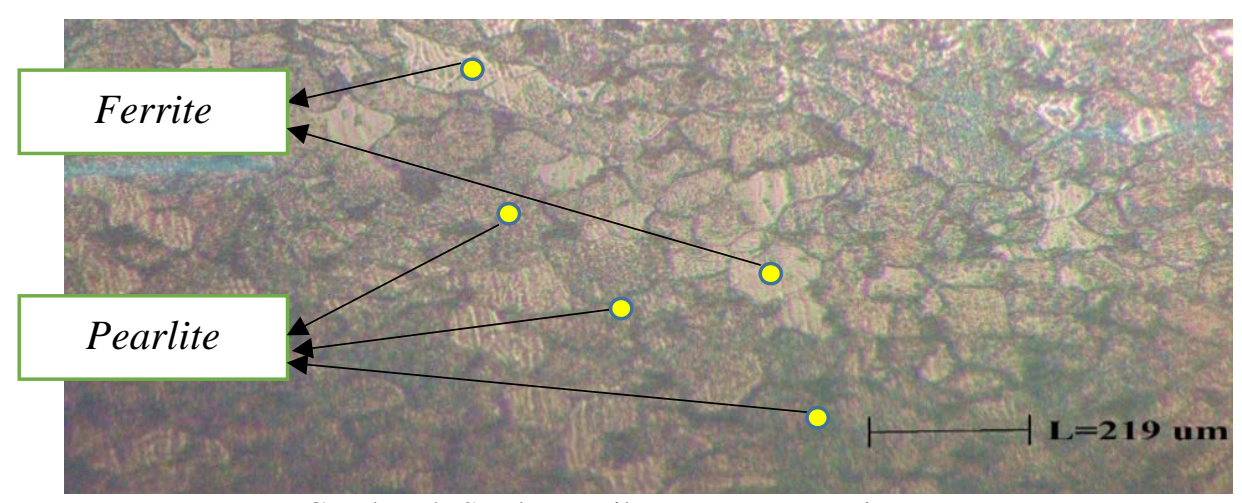

Gambar 4. Struktur Mikro Raw Material

Struktur mikro raw material tersebut tersusun atas 2 fasa utama yaitu kristal ferrite dan kristal pearlite. Kristal ferrite berwarna putih (terang) karena struktur ferrite terdiri dari logam besi murni (Fe), sedangkan kristal pearlite berwarna hitam (gelap) yang terdiri dari gabungan besi (Fe) dan karbon (C).
Pengujian menggunakan mesin puntir dinamis dengan besar sudut puntir sebesar $5^{\circ}$ dengan putaran 300/menit dilakukan pada spesimen kelompok kontrol dan eksperimen. Hasil pengujian puntir dinamis seperti ditunjukkan pada Gambar 5.

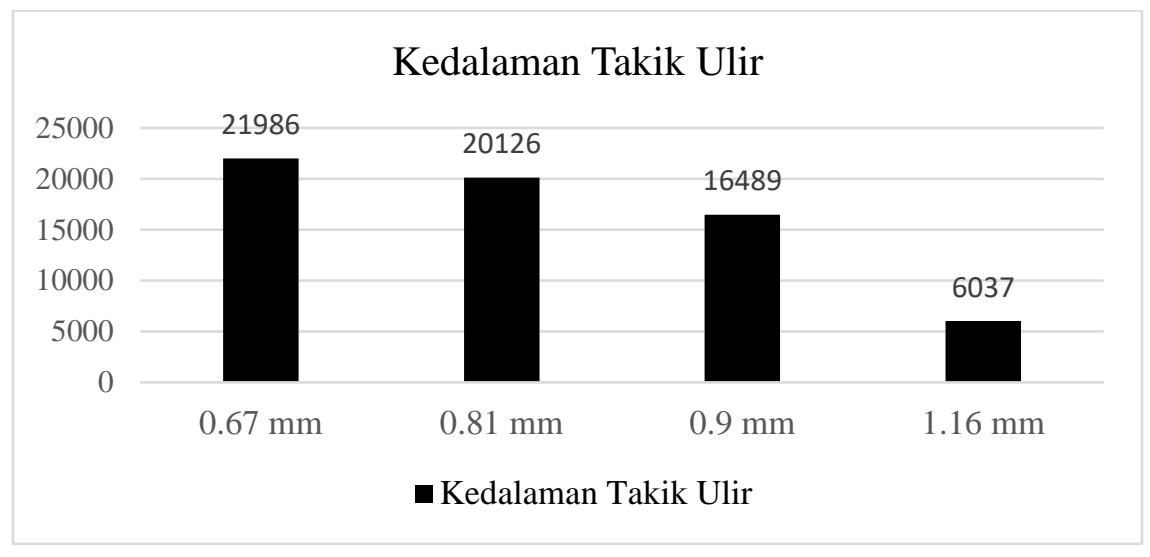

Gambar 5. Hasil Pengujian Puntir Dinamis

Hasil pengujian puntir dinamis menunjukkan bahwa ketahanan lelah ulir withworth dengan kedalaman 0,81 mm sebesar $20.126 \mathrm{~N}$ mengalami kenaikan sebesar 22,06\% dibandingkan dengan ketahanan lelah ulir withworth dengan kedalaman 0,9 mm sebesar 16.489N. Ketahanan lelah ulir withworth dengan kedalaman $0,67 \mathrm{~mm}$ sebesar $21.986 \mathrm{~N}$ mengalami kenaikan sebesar 33,34\% dibandingkan dengan ketahanan lelah ulir withworth dengan kedalaman $0,9 \mathrm{~mm}$ sebesar $16.489 \mathrm{~N}$. Ketahanan lelah ulir withworth dengan kedalaman $1,16 \mathrm{~mm}$ sebesar $6.037 \mathrm{~N}$ mengalami penurunan sebesar 63,39\% dibandingkan dengan ketahanan lelah ulir withworth dengan kedalaman 0,9 mm sebesar $16.489 \mathrm{~N}$. Hasil pengujian tersebut mengungkapkan bahwa semakin dalam takik ulir withworth, maka ketahanan lelahnya semakin menurun akibat pembebanan puntir dinamis.

Foto makro penampang patah dilakukan untuk mengetahui perilaku patahan hasil pengujian puntir dinamis. Perilaku patahan hasil pengujian puntir dinamis meliputi: initial crack, beachmark, dan final fracture. Hasil foto penampang patah seperti ditunjukkan pada Gambar 6 dan 7. 


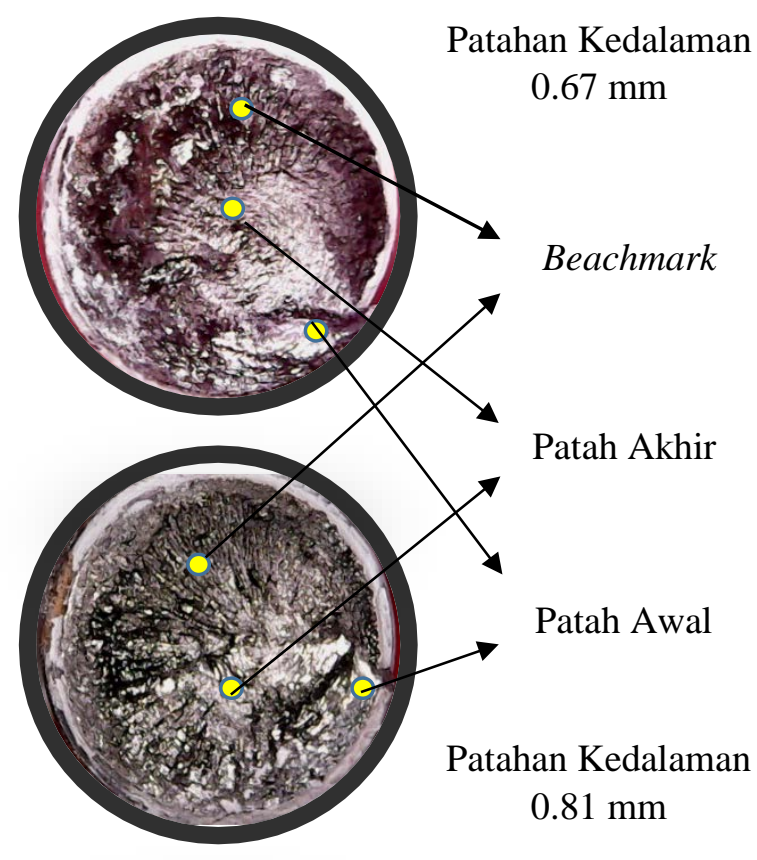

Gambar 6. Patahan Penampang dengan Kedalaman Ulir $0.67 \mathrm{~mm}$ dan $0.81 \mathrm{~mm}$

Gambar 6 menunjukkan bahwa spesimen tersebut menunjukkan adanya tanda-tanda dari patah lelah. Tanda-tanda patah lelah tersebut ditunjukkan dengan adanya beachmark (perambatan retak), patah awal (initial crack) dan patah akhir (final fracture).

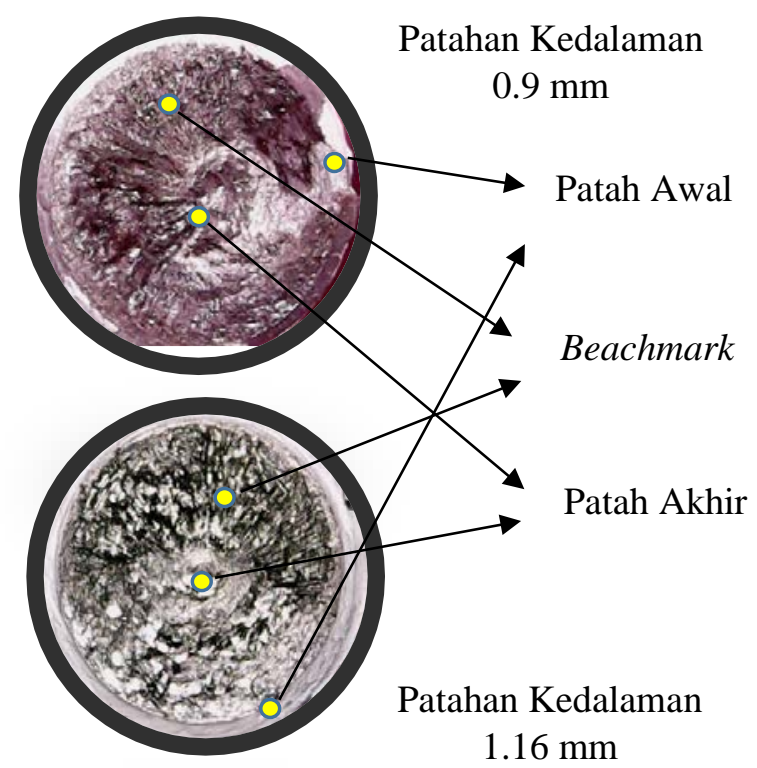

Gambar 7. Patahan Penampang dengan Kedalaman Ulir $0.9 \mathrm{~mm}$ dan $1.16 \mathrm{~mm}$
Gambar 7 menunjukkan bahwa spesimen tersebut menunjukkan adanya tanda-tanda dari patah lelah. Tanda-tanda patah lelah tersebut ditunjukkan dengan adanya beachmark (perambatan retak), patah awal (initial crack) dan patah akhir (final fracture).

Hasil penelitian menunjukkan bahwa semakin besar kedalaman takik ulir whitworth pada material baja karbon rendah semakin tinggi tingkat kegagalan fatik akibat pembebanan puntir dinamis dengan sudut puntir $5^{\circ}$. Pada pembebanan puntir dinamis, tegangan yang bekerja lebih kecil daripada ketahanan tarik atau ketahanan luluh akibat pembebanan statis. Pembebanan dinamis terjadi secara terus menerus mengakibatkan spesimen mengalami kelelahan dan akhirnya terjadi kegagalan (failure). Kegagalan yang terjadi pada spesimen disebabkan oleh beberapa faktor seperti: konsentrasi tegangan, bentuk geometri, dan pembebanan.

Pemberian takik ulir pada spesimen menyebabkan geometri permukaan spesimen menjadi tidak rata. Permukaan yang tidak rata pada spesimen menyebabkan tegangan-tegangan yang bekerja pada spesimen tidak terdistribusi secara merata. Tegangan yang bekerja pada daerah takikan ulir akan meningkat, akibatnya tegangan maksimum didaerah tersebut lebih besar dari seharusnya. Lokasi dimana terjadinya peningkatan tegangan ini disebut dengan konsentrasi tegangan. Konsentrasi tegangan sangat terpengaruh terhadap geometri permukaan spesimen (Noda et al., 2005: 151163). Ketahanan lelah menurun karena konsentrasi tegangan terjadi di setiap takik $\mathrm{V}$ di daerah ulir. Konsentrasi tegangan yang lebih dari satu tersebut saling berinteraksi dan mempengaruhi faktor konsentrasi tegangan. Interaksi akan semakin meningkatkan konsentrasi tegangan, akibatnya ketahanan lelah spesimen akan semakin menurun jika dibandingkan dengan pemberian 1 takikan (Yan et al., 2016).

Hasil penelitian menunjukkan bahwa semakin besar kedalaman ulir whitworth, ketahanan lelah pada spesimen semakin rendah. Penurunan ketahanan lelah disebabkan oleh 
konsentrasi tegangan yang terjadi pada permukaan spesimen didaerah takik ulir. Konsentrasi tegangan merupakan faktor penting dalam kegagalan dimana konsentrasi tegangan mempengaruhi tegangan maksimal yang bekerja. Semakin dalam takik ulir whitworth, maka konsentrasi tegangan semakin besar. Peningkatan konsentrasi tegangan mengakibatkan tegangan maksimal yang bekerjapun semakin besar. Peningkatan tegangan maksimal inilah yang mengakibatkan spesimen dengan kedalaman takik ulir whitworth $1.16 \mathrm{~mm}$ memiliki ketahanan lelah terendah karena tegangan maksimal yang bekerja paling tinggi dengan rata-rata siklus sebesar 6.037 siklus. Hal ini berbalik pada spesimen dengan kedalaman takik ulir whiworth $0.67 \mathrm{~mm}$ dimana tegangan maksimal yang bekerja paling kecil sehingga rata-rata siklusnya sebesar 21.986 siklus. Ketahanan lelah akan menurun seiring dengan bertambahnya kedalaman takik ulir (Araujo et al., 2011: 1092-1100, Asad et al., 2012: 94-98).

Selain faktor bentuk geometri, konsentrasi tegangan juga memiliki hubungan dengan jenis pembebanan yang diberikan pada spesimen. Jenis pembebanan mempengaruhi ketahanan dari spesimen itu yang berarti mempengaruhi ketahanan lelah dari spesimen. Konsentrasi tegangan yang terjadi pada jenis pembebanan puntir dinamis memiliki konsentrasi tegangan paling kecil dibandingkan dengan pembebanan axial dan pembebanan bending (Bader dan Njim, 2014: 819-827, Kamal et al., 2012: 291-300). Data pengujian puntir dinamis menunjukkan adanya variasi kedalaman takik ulir whitworth berpengaruh terhadap ketahanan lelah pada baja karbon rendah, dimana semakin semakin dalam takik ulir whitworth maka ketahanan lelah spesimen semakin menurun. Penuruan kekuatan lelah disebabkan oleh konsentrasi tegangan. Takikan yang diberikan pada ulir menyebabkan distribusi tegangan tidak merata di permukaan spesimen dan daerah ulir terjadi peningkatan tegangan. Takikan berupa ulir menyebabkan konsentrasi tegangan terjadi dibeberapa titik dan saling berinteraksi sama lain sehingga tegangan di daerah ulir semakin tinggi. Konsentrasi tegangan semakin meningkat dengan kedalaman takik ulir. Kedalaman takik ulir sangat mempengaruhi dari umur lelah material (Miranda et al., 2019: 250-266)

Faktor-faktor yang mempengaruhi ketahanan lelah dalam penelitian ini ada beberapa hal. Salah satu faktor adalah besar sudut yang digunakan. Besar sudut mempengaruhi besarnya pembebanan yang terjadi pada spesimen. Semakin besar sudut yang digunakan, maka ketahanan lelah akan semakin menurun (Mamidi et al., 2018: 1149-1151). Besar sudut takikan $\mathrm{V}$ pada spesimen sudah sesuai standar yaitu $60^{\circ}$. Besar sudut juga mempengaruhi ketahanan lelah dari spesimen ketika dilakukan uji puntir dinamis. Semakin kecil sudut takikan yang terbentuk, maka konsentrasi tegangan pada daerah takikan semakin besar (Rahman et al., 2008: 33163327).

Pembebanan merupakan hal yang sangat penting dalam kelalahan. Pembebanan merupakan penyebab utama terjadinya kelelahan selain dengan konsentrasi tegangan. Pembebanan yang terjadi pada spesimen terjadi secara terus menerus dalam periode yang cukup lama sehingga spesimen mengalami kelelahan dan akhirnya patah. Jenis pembebanan yang digunakan dalam penelitian ini adalah puntir dinamis. Pembebanan dengan puntir dinamis mempengaruhi ketahanan lelah karena pembebanan merupakan salah satu faktor dari batas ketahanan material. Batas ketahanan mempunyai hubungan yang sebanding dengan kekuatan lelah material. Semakin besar batas ketahanan material, maka ketahanan lelah material juga semakin besar dan begitu juga sebaliknya. Pembebanan dengan tipe puntir dinamis memiliki pengaruh paling kecil terhadap ketahanan lelah pada spesimen bertakik dari pada jenis pembebanan yang lainnya (Bader dan Kadum, 2014: 1-8). Selain jenis pembebanan, kecepatan pembebanan juga mempengaruhi kekautan lelah dari spesimen. Kecepatan pembebanan berkaitan dengan frekuensi tegangan yang diberikan kepada spesimen. Semakin tinggi putarannya, maka ketahanan lelah semakin turun (Hendrickson, 2005). 
Kecepatan pembebanan pada penelitian ini sebesar 300 rpm. Pembebanan ini termasuk besar karena siklus yang dihasilkan hingga spesimen patah terjadi dibawah $10^{5}$ siklus. Jumlah siklus yang dibawah $10^{5}$ menjadikan spesimen pada penelitian ini digolongkan ke low cyclic fatigue.

Pengamatan makroskopi dilakukan untuk mendapatkan bentuk permukaan patahan yang terjadi secara visual menggunakan kamera digital. Hasil foto makro semua spesimen setelah diuji puntir dinamis menunjukkan karakteristik dari patah lelah yang ditunjukkan oleh adanya patah awal, patah akhir dan garis pantai (beachmark) (Kwofie dan Chandler, 2001: 341345). Beachmark menjadi hal terpenting yang menandakan bahwa material tersebut mengalami patah lelah. Pola beachmarks yang muncul menunjukkan spesimen mengalami pembebanan puntir dinamis.

Takikan berupa ulir whitworth meningkatkan konsentrasi tegangan didaerah takik. Konsentrasi tegangan menyebabkan crack muncul kemudian menjalar dari permukaan menuju kedalam (pusat) spesimen. Proses perambatan dari permukaan spesimen hingga kepusat menyebabkan terjadinya beachmark. Bentuk penampang cenderung kasar menunjukkan bahwa perambatan patah yang tinggi yang disebabkan oleh penggunaan sudut yang besar. Perambatan terjadi secara terus menerus selaras dengan tegangan yang bekerja. Ketika spesimen tidak kuat lagi menahan beban puntir dinamis, maka spesimen akan mengalami kegagalan.

\section{SIMPULAN}

Hasil penelitian tentang pengaruh kedalaman takik ulir whitworth terhadap ketahanan lelah puntir dinamis pada baja karbon rendah dapat diambil beberapa kesimpulan sebagai berikut:

1. Semakin besar kedalaman takik ulir whitworth pada material baja karbon rendah semakin tinggi tingkat kegagalan fatik akibat pembebanan puntir dinamis pada sudut puntir $5^{\circ}$.
2. Patahan penampang untuk semua variasi kedalaman takik menunjukkan fenomena yang sama. Fenomena tersebut menunjukkan karakteristik dari patah lelah berupa retak awal, beachmark dan patah akhir.

\section{DAFTAR RUJUKAN}

Agrawal R, Uddanwadiker R, Padole P,Veerabu J. 2014. Effect of stress concentration in low cycle fatigue life prediction at high temperature. Journal of Basic and Applied Engineering Research. Volume 1. Nomor 2, 69-72.

Alang NA, Razak N, Miskam A. 2011. Effect of surface roughness on fatigue life of notched carbon steel. International Journal of Engineering \& Technology (IJETIJENS). Volume 11. Nomor 1, 160-163.

Araújo J, Dantas A, Castro F, Mamiya E, Ferreira J. 2011. On the characterization of the critical plane with a simple and fast alternative measure of the shear stress amplitude in multiaxial fatigue. International Journal of Fatigue. Volume 33. Nomor 8, 1092-1100.

Arola D \& Wiliams C. 2002. Estimating the fatigue stress concentration factor of machined surfaces. International Journal of Fatigue. Volume 24. Nomor 9, 923-930.

Asad A, Bjork T, Heinilla S. 2012. A finite element approach to predict the stress concentration factors in cold formed corners. International Journal of Mechanical and Mechathronics Engineering IJMME-IJENS. Volume 12. Nomor 4, 94-98.

Bader Q \& Kadum E. 2014. Effect of V notch shape on fatigue life in steel beam made of high carbon steel alloy AISI 1078. International Journal of Modern Engineering Research (IJMER). Volume 4. Nomor 7, 1-8. 
Bader Q \& Njim E. 2014. Experimental and numerical study of influence the loading mode on fatigue life in notched steel beam. International Journal of Scientific \& Engineering Research. Volume 5. Nomor 7, 819-827.

Callister Jr., William D. D. G. Rethwisch. 2011. Material science and engineering an introduction. John Wiley and Sons.

Cesnik M \& Slavic J. 2014. Vibrational fatigue and structural dynamics for harmonic and random loads. Journal of Mechanical Engineering. Volume 60. Nomor 5, 339348.

Chou TY, Tsai H, Yip MC. 2019. Preparation of CFRP with modified MWCNT to improve the mechanical properties and torsional fatigue of epoxy/polybenzoxazine copolymer. Composites Part A: Applied Science and Manufacturing. Volume 118, 30-40.

Fatemi A, Molaei R, Sharifimehr S, Shamsaei N, Phan N. 2017. Torsional fatigue behavior of wrought and additive manufactured Ti$6 \mathrm{AI}-4 \mathrm{~V}$ by powder bed fusion including surface finish effect. International Journal of Fatigue.

Ha J, Kim SK, Cobenca N, Kim H. 2013. Effect of R-phase heat treatment on torsional resistance and cyclic fatigue fracture. JOE. Volume 39. Nomor 3, 389-393.

Hendrickson D. 2005. Fatigue failure due to variable loading. Department of Computer Science, Physics, and Engineering.

Hussain F, Abdullah S, Nuawi M. Effect of temperature on fatigue life behaviour of alumunium alloy AA6061 using analytical approach. Journal of Mechanical Engineering and Sciences (JMES). Volume 10. Nomor 3, 2324-2335.
Itoh T, Sakane M, Ohsuga K. 2013. Multiaxial low cycle fatigue life under nonproportional loading. International Journal of Pressure Vessels and Piping. Volume 110, 50-65.

Kamal M, Rahman MM, Rahman AGA. 2012. Fatigue Life Evaluation of Suspension Knuckle using Multibody Simulation Technique. Journal of Mechanical Engineering and Sciences. 3:291-300.

Kwofie S \& Chandler H. 2001. Low cycle fatigue under tensile mean stresses where cyclic life extension occurs. International Journal of Fatigue. Volume 23. Nomor 4, 341-345.

La Rosa G, Lo Savio F, Pedulla E, Rapisarda E. 2017. A new torquemeter to measure the influence of heat-treatment on torsional resistance on NiTi endodontic instrumen. Elsevier, 1-12.

Liu J, Li J, Zhang Z-p. 2013. A three-parameter model for predicting fatigue life of ductile metals under constant amplitude multiaxial loading. Journal of materials engineering and performance. Volume 22. Nomor 4, 1161-1169.

Mamidi NJ, Kumar J, Nethi R, Kadali V. 2018. Impact of notch depth on the fatigue life of AISI 316L austenitic stainless steel. International Research Journal of Engineering and Technology (IRJET). Volume 5. Nomor 9, 1149-1151.

Miranda ACO, Antunes MA, Alarcon MVG, Meggiolaro MA, Castro JTP. 2019. Use of the stress gradient factor to estimate fatigue stress concentration factors $\mathrm{Kf}$. Engineering Fracture Mechanics. Volume 206, 250-266.

Mohamed SAN, Abdullah S, Arifin A, Ariffin AK, Padzi MM. 2016. Characterization of the biaxial fatigue behaviour on medium carbon steel using the strain-life approach. 
International Journal of Automotive and Mechanical Engineering (IJAME). Volume 13. Nomor 1, 3262-3277.

Noda N \& Takase Y. 2005. Stress concentration formula useful for all notch shape in a round bar (comparison between torsion, tension and bending). International Journal of Fatigue. Volume 28. Nomor 2, 151-163.

Rahman M.M, Ariffin A.K., Abdullah S., Noor M.M., Bakar R.A., Maleque M.A. 2008. Finite element based fatigue life prediction of cylinder head for two-stroke linear engine using stress-life approach. Journal of Applied Sciences. Volume 8. Nomor 19, 3316-3327.
Shang D-G, Sun G-Q, Deng J, Yan C-L. 2007. Multiaxial fatigue damage parameter and life prediction for medium-carbon steel based on the critical plane approach. International Journal of Fatigue.

Yan W, Xu Y, Wang K. 2016. Investigation of stress concentration and casing strength degradation caused by corrosion pits. International Journal of Corrosion. Volume 2016. 